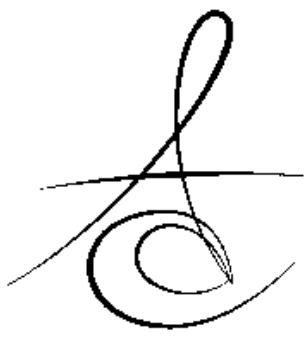

\title{
ALÇI MODELLERİN BOYUTSAL DEĞİşİKLİKLERİNİN BELİRLENMESİNDE KULLANILAN ÖLÇÜM METODLARININ KARŞILAŞTIRILMASI
}

\section{COMPARISON OF MEASUREMENT METHODS TO DETERMINE DIMENSIONAL DIFFERENCES ON DENTAL CASTS}

\author{
Dr. Öğr. Üyesi Faruk EMİR* \\ Doç. Dr. Simel AYYILDIZ* \\ Doç. Dr. Bülent PİşKİN*
}

Makale Kodu/Article code: 3469

Makale Gönderilme tarihi: $\quad 02.07 .2017$

Kabul Tarihi; 31.05 .2018

öz

Amaç: Bu çalışmanın amacı, dental alçı modeller üzerinde yapılan manuel ve dijital lineer ölçümleri karşılaştırmak ve bilgisayar destekli 3 boyutlu ölçüm yönteminin etkinliğini göstermektir.

Materyal ve Metod: Üzerinde 5 adet prepare edilmiş diş bulunan (sağ-sol I. molarlar, sağ-sol kaninler ve 1 keisici diş) mandibulayı temsil eden ark şeklinde bir ana model, bilgisayar destekli tasarım ile tasarlanmış ve bilgisayar destekli üretim (CAD/CAM) teknolojisi ile $\mathrm{CoCr}$ alaşım tozundan üretilmiştir. Ana modelden vinil siloksan eter (VSE) ile ölçü alınmış ve toplamda 10 alçı model elde edilmiştir. Ana model ve çalışma modelleri optik ekstraoral tarayıcı ile dijitalleştirilmiştir. Alçı çalışma modelleri üzerindeki manuel lineer ölçümler (VSE Manuel) dijital kumpas ile dijital modeller üzerindeki lineer ölçümler (VSE Dijital) ise 3 boyutlu (3D) analiz yazılımı ile yapılmıştır. Ayrıca çalışma modelleri üzerinde $3 \mathrm{D}$ analizler de yine aynı yazılım ile yapılmış ve renk kodlu haritalar oluşturulmuştur. Tek değişkenli varyans analizi kullanılarak farkılıklar analiz edilmiş ve çoklu karşılaştırmalar için post hoc testleri kullanılmıştır.

Bulgular: VSE Manuel ve Dijital grupları arasında istatistiksel olarak anlamlı farklılıklar bulunmuştur $(p<.001, p=.001, p=.037, p=.022)$. Dijital ölçümlerde ana modele göre farklılıklar 0.018-0.146 mm arasında değişirken, manuel ölçümlerde $0.059-0.168$ mm çıkmıştır. 3D analizlerde ise çalışma modellerinin hassasiyeti ortalama $0.0142 \mathrm{~mm}$ olarak ölçülmüş ve çalışma modelleri ana modele göre daha küçük çıkmıştır.

Sonuç: Çalışmamızda; 3D analizler ve dijital ölçümler, manuel ölçümlere göre daha hassas sonuçlar vermiş ve bulunan farklar istatistiksel olarak anlamlı çıkmıştır. Çalışma modellerinin değerlendirilmesinde, boyutları bilinen bir ana model ile bilgisayar destekli ölçüm yönteminin, objektif ve standart bir yöntem olarak kullanılabileceği düşünülmektedir.

Anahtar Kelimeler: Lineer ölçüm; dijital model; hassasiyet; bilgisayar destekli ölçüm

\section{ABSTRACT}

Aim: The purpose of this study is to compare the linear measurements with the digital measurements on dental casts and to demonstrate the effectiveness of the computer-aided 3-dimensional measurement method.

Material and Methods: An arc-shaped master model consisting of 5 prepared teeth (right-left first molars, right-left canines and one incisor) was designed with computer-aided design and fabricated with $\mathrm{CoCr}$ alloy powder using computer-aided manufacturing (CAD/CAM) technology. A total of 10 impressions were made with vinyl siloxanether (VSE) impression material from the master model. The master model and definitive casts were digitized with an optical extraoral scanner. Measurements on definitive casts (VSE Manuel) were made with digital micrometer and measurements on digitized casts (VSE Digital) with 3-dimensional (3D) analysis software. In addition, model analyzes were done with the same software and color-coded maps were created. Differences were analyzed using univariate analysis of variance and post hoc tests were used for multiple comparisons.

Results: Statistically significant differences were found between VSE Manuel and Digital groups $(p<.001$, $\mathrm{p}=.001, \mathrm{p}=.037, \mathrm{p}=.022$ ). With digital measurements differences ranged between 0.018-0.146 mm and with manuel measurements differences ranged between $0.059-0.168 \mathrm{~mm}$. According to the 3D analysis, the accuracy of the digital models was $0.0142 \mathrm{~mm}$ for average values and definitive casts were smaller than the master model.

Conclusion: In this study; 3D analysis and digital measurements shows more accurate results than manuel measurements and the differences were statistically significant. In the evaluation of the definitive casts, it is considered that computer aided measurement with a master model with known dimensions can be used as an objective and standard method.

Key Words: Linear measurement; digital model;

\section{* Sağlık Bilimleri Üniversitesi, Gülhane Diş Hekimliği Fakültesi, Protetik Diş Tedavisi Anabilim Dalı}


accuracy; computer-aided measurement

\section{GİRİ̧}

Hareketli ya da sabit bir protezden beklenen fonksiyon ve estetiğin sağlanabilmesi, protezi taşıyan dokular ya da doğal dişler ile onlara uygulanan protez arasındaki uyuma bağlıdır. Uyumlu protezlerin yapılabilmesi, sadece en uygun materyallerin değil aynı zamanda en doğru yapım tekniklerinin de seçilmesi ve hassasiyetle uygulanması ile mümkündür. ${ }^{1}$

Ölçü materyalleri, dişlerin ve çevre oral dokuların kaydını ve ilişkilerini kaydetmek ve bunları kopyalamak için kullanılır ve protetik diş hekimliğinin vazgeçilmez bir parçasıdır. ${ }^{2-4}$ Dental kliniklerde yaygın olarak kullanılan birçok elastomerik ölçü materyali vardır. ${ }^{3,5}$ Bunlardan kondansasyon silikonları, ilave tip silikonlar ve polieterler en çok tercih edilen elastomerik ölçü maddeleridir. ${ }^{3,6-8}$ Elastomerik ölçü materyalleri, yüksek hassasiyet, üstün elastik geri dönme, minimum kalıcı deformasyon ve kabul edilebilir yırtılma mukavemeti gibi özelliklere sahiptirler. ${ }^{9}$

Sabit protez restorasyonların klinik başarısında elastomerik ölçü materyallerinin boyutsal hassasiyetleri ve stabiliteleri büyük önem taşımaktadır. ${ }^{10}$ Elastomerik ölçü materyallerinde polimerizasyon reaksiyonlarının belirli bir zaman periyodunda devam ettiği ve ölçü ağızdan çıkarıldıktan sonra da sürdüğü bildirilmiştir. ${ }^{2}$ Bununla birlikte, sabit bölümlü protezlerde destek diş ve dişi çevreleyen dokuların pozitif kopyalarının, yani çalışma modellerinin de hassas bir şekilde üretilmesi gerekir. ${ }^{11}$ Ölçü aşamasında meydana gelen herhangi bir boyutsal değişim, protetik restorasyonların üretiminde kullanılan alçı çalışma modelinin de hassasiyetinin bozulmasına neden olur. ${ }^{12}$

Yapılan birçok çalışma ölçü alımı ile ilgili prosedürlerin ya da materyallerin, çalışma modellerinin hassasiyetini ve dolayısıyla protetik uyumu etkileme potansiyeline sahip olduğunu göstermiştir. ${ }^{11,13-15} \mathrm{Bu}$ çalışmalar genellikle farklı ölçü maddeleri ile üretilen çalışma modellerinin hassasiyetini etkileyip etkilemediğini manuel ölçüm yöntemleriyle araştıran çalışmalardır. ${ }^{16-18}$ Manuel ölçüm yöntemlerinde, genellikle analog ve dijital kumpaslar, profil projektörleri, elektronik dijital mikrometreler ve mikroskoplar kullanıIır. ${ }^{9,10,19}$ Bu cihazlar, çalışma modellerine ihtiyaç duyarlar ve ölçümleri sadece iki nokta arasında lineer olarak yapabilirler. Avantajları; ucuz olmaları, kullanım kolaylıkları ve hızlı sonuç vermeleridir.9,10 Ölçümlerin tekrarlanabilirliğinin düşük olması ve kullanıcı hata- larına açık olmaları en önemli dezavantajlarıdır. ${ }^{10}$ Ayrıca bu cihazlar ile sadece belirlenen noktalar arasında ölçüm yapılabildiğinden çalışma modeli üzerinden üç boyutlu veriler toplanamaz. ${ }^{5,10}$

Polimerizasyon süresince ve sonrasında, ölçü materyalleri boyutsal değişiklikler gösterdiğinden 2boyutlu ölçüm yöntemleriyle karmaşık değişimleri tespit etmek ve değerlendirmek zordur. ${ }^{5,10,20} \mathrm{Bu}$ nedenle farklı ölçü malzemelerinden yapılmış çalışma modellerinde meydana gelen boyutsal değişikliklerin tespit edilebilmesi için doğru ekipman ve ölçüm yöntemleri gereklidir.5,9,10 Son yıllarda bilgisayar destekli ölçüm (BDÖ) yöntemi, manuel yöntemin yerini almaya başlamıştır. Bu yöntem sayesinde kullanıcılara bağlı hatalar ortadan kalkmakta, çok daha kesin ve tutarlı sonuçlar elde edilebilmekte, çok küçük değişimler bile hassas bir şekilde ölçülebilebilmekte ve 3-boyutlu (3D) analizler yapılabilmektedir.,21-25

$\mathrm{Bu}$ çalışmanın amacı, çalışma modellerinde oluşan değişiklikleri manuel ve dijital lineer ölçümlerle belirlemek ve elde edilen verileri bilgisayar destekli 3D analiz yöntemi ile karşılaştırmaktır. Bu karşılaştırmayı yapmak için kullanılan başlangıç hipotezi manuel ve dijital lineer ölçümler arasında anlamlı farkların olacağıdır.

\section{MATERYAL VE METOD}

Bilgisayar destekli tasarım (CAD) yazılımı (RapidForm XOR3; 3D Systems Inc., SC, ABD) ile 14 $\mathrm{mm}$ yüksekliğinde ve $16 \mathrm{~mm}$ genişliğinde alt çeneyi taklit eden bir ark tasarlandı. Yükseklikleri $10.15 \mathrm{~mm}$ olan, sağ mandibular birinci molar ve kanin, santral kesici, sol mandibular birinci molar ve kanin dişlerini temsil eden 6 derecelik aksiyal eğime sahip ve $1 \mathrm{~mm}$ shoulder basamağı olan beş prepare edilmiş diş, ark üzerine yerleştirildi. Prepare edilmiş dişlerin oklüzal yüzeylerinin ortasına yarım-küre (1.4-mm çap) şeklinde bir çıkıntı eklendi ve ölçümler için referans noktası olarak kullanıldı. Dijital veri stereolitografi formatında (.stl) kaydedildi (Resim 1A). Dijital veri direkt metal lazer sinterleme (DMLS) ünitesine (M2, Concept Laser, Hoffmann, Innovation Group, Lichtenfels, Almanya) aktarıldı ve ana model CoCr (Remanium Star, Dentaurum Gmbh \& Co. KG, Ispringen, Almanya) metal alaşım tozuyla imal edildi (Resim 1B).

Ana modelin ölçüsü, hazır kaşık ve aljinat ölçü maddesi (Phase Plus, Zhermack, Badia Polesine, RO,

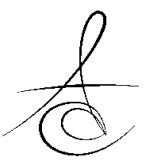


İtalya) ile alındı. Tip IV dental alçı (FujiRock, GC Europe, Leuven, Belçika) ile modeller hazırlandı ve kişiye özel kaşıklar oto polimerizan akrilik materyali (Meliodent; Heraeus Kulzer $\mathrm{GmbH}$, Hanau, Almanya) ile imal edildi. İki polistiren plaka (12 x $20 \times 20 \mathrm{~mm})$ ve 4 kılavuz metal çubuk ile bir ölçü alma aparatı oluşturuldu. Ana model alt polistiren plakanın ortasına sabitlendi.

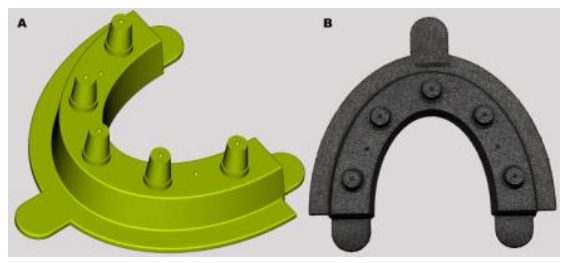

Resim 1. A: Ana modelin stereolitografi (.stl) formatında tasarlanmış dijital verisi. B: $\mathrm{CoCr}$ alaşım tozu kullanılarak CAD/CAM teknolojisi ile üretilmiş ana model.

Ölçü işlemleri için vinil siloksan eter (VSE) elastik ölçü maddesi ve tek aşamalı ölçü tekniği kullanıldı. VSE (Identium Heavy; Kettenbach, Kettenbach $\mathrm{GmbH}$ \& Co. KG, Eschenburg, Almanya) ölçü maddesi otomatik karıştırıcıdan (Pentamix II, 3M ESPE, Seefeld, Almanya) kişiye özel kaşıklara eşit miktarda konuldu ve ana model üzerine de light body VSE (Identium Light; Kettenbach, Kettenbach $\mathrm{GmbH}$ \& Co. KG, Eschenburg, Almanya) ölçü materyali otomatik tabanca sistemi ile enjekte edildi ve kaşık ana model üzerine yerleştirildi. Ölçüler polimerizasyon için $10 \mathrm{dk}$ boyunca ölçü aparatı üzerinde bekletildi ve sonrasında ana modelden ayrıldı.

Tüm alçı modeller, $150 \mathrm{gr} / 30 \mathrm{ml}$ 'lik bir toz su oranında Tip IV dental alçı (FujiRock, GC Europe, Leuven, Belçika) kullanılarak elde edildi. Tip IV dental alçı, üretici tavsiyesine göre el ile 15 sn ve vakumlu mekanik karıştırma cihazı (Degussa Multivac 4; Degussa AG, Almanya) ile 45 sn karıştırıldı. Her alçı model titreşim altında döküldü (Degussa Vibrator R2; Degussa AG, Almanya) ve oda sıcaklığında 2 saat bekletildi. Toplamda 10 adet alçı çalışma modeli oluşturuldu. Ana model, bir optik tarayıcı (3Shape D700, Copenhagen, Danimarka) ile dijitalleştirildi ve sanal referans ana modeli elde edildi. On alçı modelin sanal veri haline getirilmesi için aynı optik tarayıcı kullanıldı ve 10 sanal çalışma modeli elde edildi. Elde edilen dijital ve alçı çalışma modelleri üzerinde 7 ayrı ölçüm bölgesi planlandı. Molar dişler arasındaki mesafe
"Ölçüm 1", molarlar ile kesici diş arasındaki mesafe "Ölçüm 2 ve 3", molarlar ile kaninler arasındaki mesafe "Ölçüm 4 ve 7", kaninler ile kesici diş arasındaki mesafe "Ölçüm 5 ve 6" olarak planlanmıştır (Resim 2). Ölçüm için referans noktaları belirlendikten sonra hazırlanan çalışma modelleri üzerinde, dijital kumpas (Mitutoyo Absolute digimagic CD-15CPX Mitutoyo Corp. Kawasaki, Japonya) kullanılarak lineer manuel ölçümler yapıldı (Resim 3A). Manuel ölçümlerin yapıldığı grup VSE Manuel olarak belirlendi. Sanal çalışma modelleri üzerinde ise bir CAD analiz programı (RapidForm XOV3; 3D Systems Inc., SC, ABD) kullanılarak ölçümler tekrarlandı (Resim 3B). Dijital ölçümlerin yapıldığı grup VSE Dijital olarak belirlendi. Ölçümler tek ve aynı araştırmacı tarafından yapıldı. Belirlenen noktalardan çoklu ölçümler yapıldı ve bu ölçümlerin ortalaması alınarak veriler kaydedildi. Yapılan tüm ölçümlerde metrik birim olarak milimetre kullanıldı.

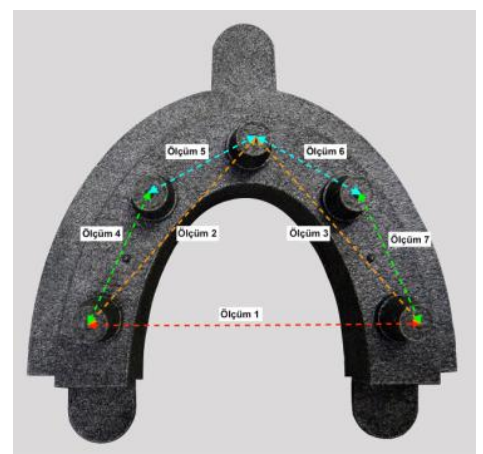

Resim 2. Ana model ve çalışma modelleri üzerinde lineer ölçümlerin yapıldığı 7 bölgenin model üzerinde gösterimi.

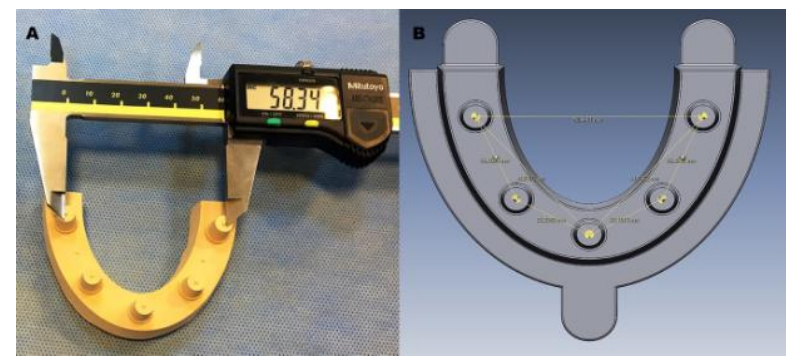

Resim 3 A. Alçı çalışma modeli üzerinde dijital kumpas ile yapılan lineer manuel ölçüm. B: Sanal çalışma modeli üzerinde 3D yazılım ile yapılan lineer dijital ölçümler.

$\mathrm{Bu}$ iki grup arasındaki ölçüm farklarının istatistiksel olarak değerlendirilmesi (SPSS, IBM Inc.,

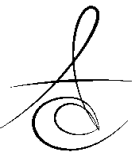


Chicago, ABD) için Tek-yönlü ANOVA ve grup içi karşılaştırmalarda Tukey HSD testleri yapıldı. Bunlara ek olarak 3D analiz programı (RapidForm XOV3; 3D Systems Inc., SC, ABD) ile en uygun hizalama yöntemi (best-fit alignment) algoritması kullanılarak modellerin tüm yüzeyinde oluşan deformasyonlar 3D değerlendirmeye tabi tutuldu. Değişimleri gösteren renk kodlu 3D haritalar oluşturuldu ve istenilen noktalardan veriler elde edildi (Resim 4). Ayrıca ayrıntılı incelemeler için CAD analiz programı ile dijital çalışma modelleri üzerinden çoklu kesitler alındı (Resim 5A). X-Z düzleminde alınan kesitte kırmızı çizgiler ana modeli, siyah çizgiler ise çalışma modelini göstermektedir (Resim 5B). Böylece alınan kesitler ile incelenmek istenen bölgede ana modele göre oluşan farklılıklar iki boyutlu olarak da takip edilebilmektedir.

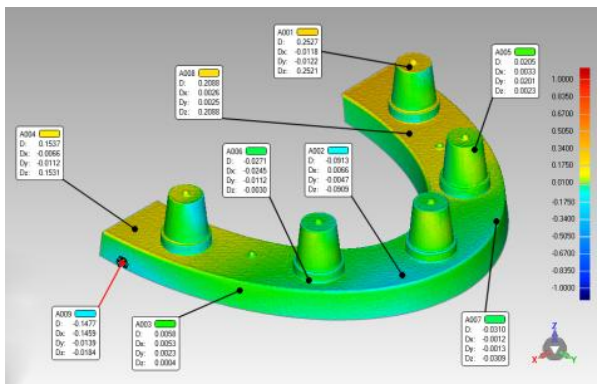

Resim 4. Sanal çalışma modelinde 3D yüzey analizi sonrasında elde edilen veriler ve bunların renk kodlu haritası. Yeşil alanlar $\pm 0.010 \mathrm{~mm}$ ye kadar olan değişiklikler göstermektedir. Sarı-kırmızı alanlar $\left(0.010 \mathrm{~mm}^{\prime}\right.$ den $1 \mathrm{~mm}^{\prime}$ ye): Ana modele göre oluşan genişleme. Açık mavi-koyu mavi alanlar (-0.010mm den $-1 \mathrm{~mm}$ 'ye): Ana modele göre oluşan küçülme. D: Ana modele göre farklılığın ortalama değeri $(\mathrm{mm})$. Dx: X ekseninde ana modele göre oluşan değişim değeri $(\mathrm{mm})$. Dy: $Y$ ekseninde ana modele göre oluşan değişim değeri $(\mathrm{mm})$. Dz: Z ekseninde ana modele göre oluşan değişim değeri $(\mathrm{mm})$.

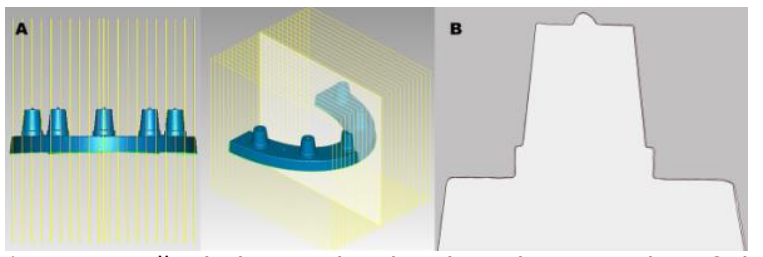

*Resmin sağ alt köşesinde eksenlerin hangi yönleri ifade ettiği gösterilmiştir.

Resim 5. A: Sanal çalışma modeli üzerinde ayrıntılı değerlendirme için $X-Y$ düzleminde çok sayıda kesit alınması. B: Dayanak üzerinden $X-Z$ düzleminde alınan kesit ile değişimlerin 2D olarak görüntülenmesi.

*Kırmızı renkli çizgiler ana modeli, siyah renkli çizgiler ise sanal çalışma modelini temsil etmektedir.

\section{BULGULAR}

Ana model ile çalışma modelleri arasındaki farklar ölçüm yöntemlerine göre karşılaştırılığında ortaya çıkan sonuçlar Resim 6' da verilmiştir. Manuel ölçümlerin ortalaması Ölçüm 1'den 7'ye sırasıyla 58.34 $\mathrm{mm}, 44.64 \mathrm{~mm}, 44.65 \mathrm{~mm}, 26.36 \mathrm{~mm}, 22.04 \mathrm{~mm}$, $22.09 \mathrm{~mm}, 26.37 \mathrm{~mm}$ olarak bulunmuştur. Dijital ölçümlerin ortalaması ise Ölçüm 1 'den 7 'ye sırasıyla $58.42 \mathrm{~mm}, 44.59 \mathrm{~mm}, 44.61 \mathrm{~mm}, 26.37 \mathrm{~mm}, 22.06$ $\mathrm{mm}, 22.13 \mathrm{~mm}, 26.37 \mathrm{~mm}$ olarak bulunmuştur. Tek yönlü ANOVA testine göre Ana model, VSE Manuel ve Dijital grupları arasındaki farklar istatistiksel olarak anlamlıdır $(\mathrm{p}<.001, \mathrm{p}=.001, \mathrm{p}=.037, \mathrm{p}=.022$ ) (Tablo 1).

Tablo 1. Tek yönlü ANOVA testi gruplar arası karşılaştırma sonuçları.

\begin{tabular}{|l|l|l|l|l|l|}
\hline & SS & df & MS & F & P \\
\hline Ölçüm 1 & 0.056 & 2 & 0.028 & 13.384 & $<\mathbf{0 . 0 0 1}$ \\
\hline Ölçüm 2 & 0.094 & 2 & 0.047 & 37.873 & $<\mathbf{0 . 0 0 1}$ \\
\hline Ölçüm 3 & 0.079 & 2 & 0.040 & 9.822 & $\mathbf{0 . 0 0 1}$ \\
\hline Ölçüm 4 & 0.029 & 2 & 0.015 & 3.719 & $\mathbf{0 . 0 3 7}$ \\
\hline Ölçüm 5 & 0.167 & 2 & 0.083 & 27.164 & $<\mathbf{0 . 0 0 1}$ \\
\hline Ölçüm 6 & 0.070 & 2 & 0.035 & 15.700 & $<\mathbf{0 . 0 0 1}$ \\
\hline Ölçüm 7 & 0.023 & 2 & 0.011 & 4.407 & $\mathbf{0 . 0 2 2}$ \\
\hline
\end{tabular}

SS: kareler toplamu, MS: kareler ortalaması $P<0.05$ istatiksel farklılık gruplar arası etkileşim varlığını gösterir.

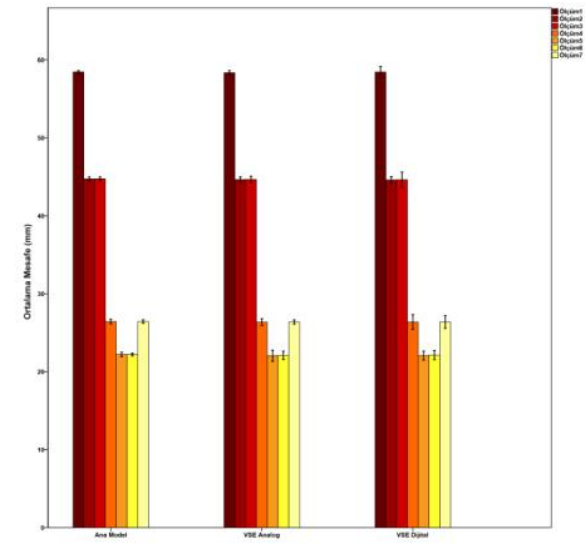

Resim 6. Ana model ile çalışma modelleri karşıllaştıııldı̆ında ortaya çıkan sonuçları gösteren grafik.

Ölçüm sonuçlarına göre Ölçüm 1 ve $4^{\prime}$ te ana modele göre sadece VSE Manuel grubunda istatistiksel olarak anlamlı farklııklar bulunmuştur $(p<0.001$, $p=0.044$ ). Ölçüm 2,3,5,6 ve $7^{\prime}$ de ise her iki grupta da ana modele göre istatistiksel olarak anlamlı farkllık bulunmuştur (Tablo 2). Lineer farkllıklar VSE Manuel grubunda $0.059 \mathrm{~mm}$ ile $0.168 \mathrm{~mm}$ arasında, VSE

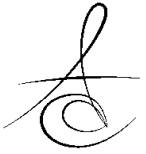


Dijital grubunda ise $0.018 \mathrm{~mm}$ ile $0.146 \mathrm{~mm}$ arasında değişmektedir. 3D analizlere göre ana model ile değerlendirilen çalışma modelinin tüm yüzeyleri arasındaki fark ise ortalama $0.0142 \mathrm{~mm}$ 'dir ve çalışma modelleri ana modele göre daha küçük çıkmıştır. Resim 4' de değerlendirilen modele ait renk kodlu harita görülmektedir. Renk kodlu haritada yeşil renkli alanlar ana modele boyut olarak en yakın bölgeleri ( $\pm 0.010 \mathrm{~mm}$ ) gösterirken sarı-kırmızı arası olan renkler ana modele göre ekspansiyonun görüldüğü bölgeleri ve açık mavi-koyu mavi arasındaki renkler ise ana modele göre kontraksiyonun görüldüğü bölgeleri göstermektedir. A001-A009 noktaları ise istenilen bölgeler üzerinden alınan ölçümleri göstermektedir. Bu ölçümler üzerinde görülen $X, Y$ ve $Z$ koordinatlarındaki mesafe değerleri, bu koordinatlarda oluşan boyutsal değişim miktarlarını göstermektedir. Resim $5 A^{\prime}$ da ise Y-Z düzleminde çok sayıda kesit alınarak model üzerinde istenilen bölgede ana model ile çalışma modeli arasındaki farkların incelenebileceği gösterilmiştir. Resim 5B' de ise X-Z düzlemindeki kesitte çalışma modelinin ana modelden farklılıkları ayrıntılı bir şekilde takip edilmektedir. Kırmızı renkli çizgi ana modeldeki dayanağı belirtirken siyah çizgi ise çalışma modelinde bulunan dayanağı göstermektedir. Buna göre çalışma modeli ana modele göre lingualde bir miktar kontraksiyona uğramış gözükmektedir. Ayrıca basamağın lingualinde keskin hatlar tarama sonrası yerini daha yuvarlak hatlara bırakmış olarak görülmektedir.

Tablo 2. Grup içi karşılaştırmalardan elde edilen veriler.

\begin{tabular}{|l|l|l|l|l|l|}
\hline \multirow{2}{*}{} & \multirow{2}{*}{ Gruplar } & \multicolumn{2}{l|}{$\begin{array}{l}\text { Ortalama } \\
\text { Fark }\end{array}$} & $\begin{array}{l}\text { Standart } \\
\text { Hata }\end{array}$ & P \\
\hline \multirow{2}{*}{ Ölçüm 1 } & \multirow{2}{*}{$\begin{array}{l}\text { Ana } \\
\text { Model }\end{array}$} & Manuel & $0,099^{*}$ & 0.020 & $<0.001$ \\
\cline { 3 - 6 } & Dijital & 0,018 & 0.020 & 0.655 \\
\hline \multirow{2}{*}{ Ölçüm 2 } & Ana & Manuel & $0,089^{*}$ & 0.015 & $<0.001$ \\
\cline { 3 - 6 } & Model & Dijital & $0,135^{*}$ & 0.015 & $<0.001$ \\
\hline Ölçüm 3 & \multirow{2}{*}{ Ana } & Manuel & $0,084^{*}$ & 0.028 & 0.017 \\
\cline { 3 - 6 } & Model & Dijital & $0,123^{*}$ & 0.028 & 0.001 \\
\hline Ölçüm 4 & Ana & Manuel & $0,071^{*}$ & 0.028 & 0.044 \\
\cline { 3 - 6 } & Model & Dijital & 0,060 & 0.028 & 0.100 \\
\hline Ölçüm 5 & Ana & Manuel & $0,168^{*}$ & 0.024 & $<0.001$ \\
\cline { 3 - 6 } & Model & Dijital & $0,146^{*}$ & 0.024 & $<0.001$ \\
\hline \multirow{2}{*}{ Ölçüm 6 } & Ana & Manuel & $0,117^{*}$ & 0.021 & $<0.001$ \\
\cline { 3 - 6 } & Model & Dijital & $0,076^{*}$ & 0.021 & 0.004 \\
\hline Ölçüm 7 & Ana & Manuel & $0,059^{*}$ & 0.022 & 0.039 \\
\cline { 3 - 6 } & Model & Dijital & $0,058^{*}$ & 0.022 & 0.043 \\
\hline
\end{tabular}

*Ortalama fark değerleri mm olarak verilmiştir.

\section{TARTIŞMA}

Çalışmamızda, çalışma modellerinde oluşan boyutsal değişimlerin hesaplanmasında kullanılan manuel ve dijital ölçüm metodları karşılaştırımıştır.
Buna göre dijital ölçümler, manuel ölçümlere göre daha hassas sonuçlar vermiş ve $3 D$ analizler ile çalışma modellerinde oluşan değişimler $X, Y$ ve $Z$ koordinatlarında değerlendirilmiştir. Böylece çalışmanın çıkış hipotezi onaylanmıştır.

Ölçümlerde şekil ve boyutları bilinen bir ana modelin kullanılması ölçüm sonuçlarının kesinliğini ve hassasiyetini arttırmaktadır. ${ }^{26}$ Önceki benzer çalışmalarda, ana modeller lineer veya ark şeklinde tasarlanmıştır. Bununla birlikte ana modelin lineer olmasının dental arkları taklit edemeyeceğini bildiren çalışmalar da mevcuttur. ${ }^{10,27}$ Ayrıca bazı araştırıcılar, ark şeklinde ana modellerin, dental arkları daha iyi taklit ettiğini, bu nedenle bu tip çalışmalarda, tam ark ana model kullanılmasının uygun olacağını bildirmişlerdir. ${ }^{10,27}$

Lineer in vitro modeller genellikle bir, iki ya da üç dayanaktan oluşmaktadır. ${ }^{10,28-31}$ Oysa, önceki çalışmalarda kullanılan ark şeklinde ana modeller, dört, beş ya da altı dayanaktan oluşmaktadır. ${ }^{19,32,33}$ Çalışmamızda, ortaya çıkabilecek boyutsal değişikliklerin daha iyi gözlenebilmesi için, ana model üzerinde, boyutu birbirine eşit 5 adet dayanak kullanılmıştır. Böylece, boyutsal sapmaların en çok hangi bölgede (posterioranterior) oluştuğunun belirlenmesi amaçlanmıştır.

Önceki çalışmalarda, üretilen çalışma modeli ile ana model arasındaki boyutsal farklılıklar, manuel kumpaslar, dijital kumpaslar, profil projektörleri, elektronik dijital mikrometreler ve mikroskop gibi gereçler kullanılarak ölçülmüştür. Bu yöntemlerin tümü, manuel yöntem olarak bilinir ve ölçüm sonuçları uygulayıcı farklılığına açıktır.9,10,19 Çalışma modellerinde oluşan boyutsal değişimlerin, objektif, tekrarlanabilir ve uygulayıcı farklılığından etkilenmeyen bir yöntem ile ölçülebilmesi, çalışma başarısı açısından çok önemlidir. 5,9,10 Bu nedenle çalışmamızda, tekrarlanabilir ve aynı zamanda hassas, uygulayıc farklılığından etkilenmeyen bir ölçüm yöntemi olan BDÖ kullanılmıştır. BDÖ’nün diğer önemli avantajı, üç boyutlu değerlendirmelerinin yapılabilmesine olanak vermesidir.9,15,21-25,34 Manuel yöntemlerde ölçümler sadece tek bir hatta mesafe değerleri verecek şekilde hesaplanır. Oysa BDÖ'de, çalışma modellerinin tamamında oluşan boyutsal değişiklikler hesaplanıp, sayısal verilere dönüştürülür. Buna ek olarak, bu boyutsal değişiklikler, görsel veri olarak sunulmak istendiğinde, üç boyutlu renk kodlu haritalar da oluşturulabilir. Boyutsal değişiklikler, koordinat sisteminde gösterilmek istendiğinde, ana model üzerinde seçilen bir noktanın, karşılaş- 
tırma yapılacak çalışma modelindeki eşdeğerleriyle, $X$, $Y, Z$ koordinatlarına göre, uzaysal konum değişimleri ve bu değişimlerin yönleri de belirlenebilir. $X$ koordinatında oluşan değişimler mediolateral yönde, $Y$ koordinatında oluşan değişimler anteroposterior yönde ve $Z$ koordinatında oluşan değişimler ise oklüzogingival yönde oluşan farklılığı gösterir (Resim 4). Örneğin; Z koordinatındaki değişimin pozitif veya negatif olması, dayanak üzerine yapılacak restorasyonun infraoklüzyonda ya da supraoklüzyonda olacağını belirtir.

Sabit protetik restorasyonların üretim sonrasında dayanak dişler ile pasif uyuma sahip olması istenir. Pasif uyuma sahip protetik restorasyonların üretilebilmesi için en önemli faktörlerden birisinin ölçü maddesi olduğu söylenmektedir. ${ }^{35}$ Stober ve ark. ${ }^{36}$ göre polivinil siloksan (PVS), polieter (PE) ve VSE ölçü maddeleri klinik olarak kabul edilebilir sonuçlar vermektedir. Nassar ve ark. ${ }^{17}$ ise VSE ölçü maddesinin PE ve PVS ölçü maddelerinden daha hassas sonuçlar verdiğini bildirmiştir. Yapılan bazı çalışmalara göre tam ark alçı çalışma modellerinin hassasiyeti $0.01 \mathrm{~mm}$ ile $0.06 \mathrm{~mm}$ arasında değişmekteyken, 22,25,27,37-39 çalışmamıda modellerin hassasiyeti ortalama olarak 0.014 $\mathrm{mm}$ olarak bulunmuştur. Bu farklılıkların sebebinin çalışmalardaki metotların farklı olması, birbirinden farklı ana modellerin ve ölçü maddelerinin kullanımı olduğu düşünülmektedir.

Çalışmamızda kullanılan ölçü materyali için polimerizasyon büzülmesinin yaklaşık $\% 0.2$ olduğu ve tip IV dental alçının ekspansiyonun ise \%0.09 olduğu üretici firmalar tarafından bildirilmiştir. Alçının ekspansiyon değeri, ölçü materyalinin büzülme değerini kompanse edemediği için çalışma modellerinin ana modelden daha küçük olduğu değerlendirilmiştir. Bununla birlikte ölçü maddesinin, ölçü kaşığının duvarlarına doğru büzülmesi çalışma modellerinin ana modelden daha küçük boyutta çıkmasına sebep olduğu düşünülmektedir. Bu durum ölçülen noktalar arasındaki uzakIıkların ana modele göre daha düşük çıkmış olmasını da açıklamaktadır. Ayrıca ölçü kaşığının yan duvarlarının temas yüzeyi kaşığın üst yüzey temas alanından büyük olduğu için ölçü materyali kaşığın üst yüzeyine doğru büzülmekte ve bu da çalışma modelindeki dayanakların daha küçük çıkmasına sebep olmaktadır. Çalışma modellerinde oluşan değişimler sadece lineer ölçümler ile değerlendirildiğinde elde edilen veriler 3D ölçümlere göre yetersiz kalmaktadır. Çünkü lineer ölçümlerde belirlenen 2 nokta arasında çalışılırken elde edilen değerler modelin sadece ölçüm yapılan bölgesi hakkında bilgi verir fakat modelin tüm yüzeylerinde oluşan boyutsal değişim hakkında bilgi vermez. Fiziki modeller tarama işlemleri sonucunda sanal veri haline getirilirken nokta bulutlarına dönüştürülürler. Bu nokta bulutlarının yoğunlukları ise kullanılan programların algoritmalarına göre değişmektedir. 3D analiz programları sanal verideki noktalardan ölçüm yapmaktadır. Bu nedenle 3D ölçümlerde, ölçüm yapılan nokta sayısı verinin yoğunluğuna göre 100.000 ve daha yukarısına çıkabilmektedir. Ölçüm yapılan nokta sayısı da 3D analiz programı tarafından verilmektedir. Bu da ölçüm yapılan modelin tüm yüzeyleri boyunca oluşan değişikliklerin saptanmasına ve modelin tamamının hassasiyeti hakkında bilgi edinmemize olanak verir. Çalışmamızda 3D analiz ölçümleri sanal modeller üzerinde 478.000 noktadan yapılmıştır. Alınan kesitler incelendiğinde, fiziki modellerin sanal hale getirlmesi sonrasında keskin basamak kenar hatlarının yuvarlaklaştığı ve genel olarak ana modele yakın geçişlerin olduğu görülmüştür. Dayanakların bazılarında ise üst yüzeylerde ana modele göre bir miktar genişleme ve basamaklarda ise bir miktar büzülme olduğu gözlemlenmiştir.

Protetik restorasyonların başarısında; diş preparasyonu, ölçü maddesi ve yöntemi, çalışma modelinin hassasiyeti ve restorasyonun üretim yöntemi gibi birçok faktör önemli rol oynamaktadır. ${ }^{40}$ Bazı araştırmacılara göre sabit protetik restorasyonlarda klinik olarak kabul edilebilir uyum 0.1 mm'nin altında olmalıdır. ${ }^{41,42}$ Çalışmamızda VSE ölçü maddesi ile üretilen tam ark alçı modellerin hassasiyeti $0.014 \mathrm{~mm}$ olarak bulunmuştur. Bu sonuç, protezin bitimine kadar laboratuvarda yapılacak işlemler sonrasında bazı boyutsal değişimlerin olacağı da düşünüldüğünde klinik olarak kabul edilebilir bir değişikliktir. Kullanılan ölçü maddelerinin ağız dokularını ne doğrulukla yansıtabildiğinin gösterilmesi, ayrıca alçı ve ölçü maddelerinde oluşan boyutsal değişikliklerin sabit protez üretimine etkisinin güncel yöntemlerle değerlendirilmesinin hekimlere klinikte güvenilir bir rehber oluşturacağı düşünülmektedir.

\section{SONUÇ}

Çalışmamızda;

1. Dijital ölçüm yöntemleri manuel ölçüm yöntemlerinden daha başarılı sonuçlar vermiştir.

2. Çalışma modellerindeki değişimler manuel ölçümlerle kıyaslandığında BDÖ sayesinde çok daha fazla noktadan ölçümler yapılarak belirlenmiş ve bunlar 
görsel veri halinde sunulmuştur.

3. VSE ölçü maddesi kullanılarak oluşturulan çalışma modellerinin boyutsal değişiklikleri klinik olarak kabul edilebilir boyuttadır.

4. Çalışma modellerinin değerlendirilmesinde, boyutları bilinen bir ana model ile BDÖ yönteminin, objektif ve standart bir yöntem olarak kullanılabileceği düşünülmektedir.

Faruk Emir: ORCID ID: 0000-0003-3538-2582

Simel Ayyıldız: ORCID ID: 0000-0003-4679-0629

Bülent Pişkin: ORCID ID: 0000-0003-4233-2858

\section{KAYNAKLAR}

1. Cole MA, Jankousky KC, Bowman CN. Thiol-ene functionalized siloxanes for use as elastomeric dental impression materials. Dent Mater 2014;30:449-55.

2. Wadhwani CP, Johnson GH, Lepe $X$, Raigrodski AJ. Accuracy of newly formulated fast-setting elastomeric impression materials. J Prosthet Dent 2005; 93:530-9.

3. Chen SY, Liang WM, Chen FN. Factors affecting the accuracy of elastometric impression materials. J Dent 2004;32:603-9.

4. Çağlar İ, Yeşil Duymuş Z, Ateş SM. Diş hekimliğinde kullanılan ölçü sistemlerinde güncel yaklaşımlar: dijital ölçü. Atatürk Diş Hek Fak Derg 2015; 10: 135-40.

5. Rudolph H, Graf MRS, Kuhn K, Rupf-Köhler S, Eirich A, Edelmann C, Quaas $S$, Luthardt RG. Performance of dental impression materials: Benchmarking of materials and techniques by three-dimensional analysis. Dent Mater J 2015; 34: 572-84.

6. O'Brien WJ. Dental Materials and Their Selection. 3 ed. Illnois; Quintessence Publishing: 2002; p. 90113.

7. McCabe JF, Walls AWG. Applied Dental Materials. 9 ed. Oxford; Blackwell Publishing: 2008. p. 136-46.

8. Rosentiel SF, Land M, Fujimoto J. Contemporary Fixed Prosthodontics. 4 ed. St Louis; Mosby Elsevier: 2006. p. 431-65.

9. Brosky ME, Major RJ, DeLong R, Hodges JS. Evaluation of dental arch reproduction using threedimensional optical digitization. J Prosthet Dent $2003 ; 32: 434-40$.

10. Shah S, Sundaram G, Bartlett D, Sherriff M. The use of a 3D laser scanner using superimpositional software to assess the accuracy of impression techniques. J Dent 2004;32:653-8.

11. Meral YE, Akça K. İki Farklı Polivinil Silikon Ö Içü Maddesinin Boyutsal Hassasiyetlerinin Karșilaștırıl ması. Hacettepe Diş Hek Fak Derg 2010;34:21-8.

12. Lamis AH. Accuracy of Optimized Rubber Base Impression Materials (Linear and Surface Analysis). Aust J Basic Appl Sci 2014;8:543-51.

13. Kang $A H$, Johnson $G H$, Lepe $X$, Wataha JC. Accuracy of a reformulated fast-set vinyl polysiloxane impression material using dual-arch trays. J Prosthet Dent 2009;101:332-41.

14. Johnson GH, Mancl LA, Schwedhelm ER, Verhoef $D R$, Lepe $X$. Clinical trial investigating success rates for polyether and vinyl polysiloxane impressions made with full-arch and dual-arch plastic trays. J Prosthet Dent 2010;103:13-22.

15. Luthardt RG, Walter MH, Weber A, Koch R, Rudolph $\mathrm{H}$. Clinical parameters influencing the accuracy of 1 and 2-stage impressions: a randomized controlled trial. Int J Prosthodont 2008; 21:322-7.

16. Kambhampati S, Subhash V, Vijay C, Das A. Effect of temperature changes on the dimensional stability of elastomeric impression materials. J Int Oral Health 2014;6:12-9.

17. Nassar U, Oko A, Adeeb S, El-Rich M, Flores-Mir C. An in vitro study on the dimensional stability of a vinyl polyether silicone impression material over a prolonged storage period. J Prosthet Dent 2013; 109:172-8.

18. Dugal R, Railkar B, Musani S. Comparative evaluation of dimensional accuracy of different polyvinyl siloxane putty-wash impression techniques-in vitro study. J Int Oral Health 2013; 5: 85-94.

19. Wee AG, Cheng AC, Eskridge RN. Accuracy of 3 conceptually different die systems used for implant casts. J Prosthet Dent 2002;87:23-9.

20. Chandran DT, Jagger DC, Jagger RG, Barbour ME. Two- and three-dimensional accuracy of dental impression materials: effects of storage time and moisture contamination. Biomed Mater Eng 2010;20:243-9.

21. Güth JF, Keul C, Stimmelmayr M, Beuer F, Edelhoff $D$. Accuracy of digital models obtained by direct and indirect data capturing. Clin Oral Invest 2013;17:1201-8.

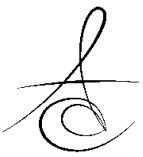


22. Ender A, Mehl A. Accuracy of complete-arch dental impressions: a new method of measuring trueness and precision. J Prosthet Dent 2013;109:121-8.

23. Jeon JH, Lee KT, Kim HY, Kim JH, Kim WC. White light scanner-based repeatability of 3- dimensional digitizing of silicon rubber abutment teeth impressions. J Adv Prosthodont 2013;5:452-6.

24. Emir F, Piskin B, Sipahi C. Effect of dental technician disparities on the 3-dimensional accuracyof definitive casts. J Prosthet Dent 2017; 117: 410-8.

25. Cho SH, Schaefer O, Thompson GA, Arndt G. Comparison of accuracy and reproducibility of casts made by digital and conventional methods. J Prosthet Dent 2015;113:310-5.

26. Potran M, Strbac B, Puskar T, Hadzistevic M, Hodolic J, Trifkovic B. Measurement of accuracy of dental working casts using a coordinate measuring machine. Vojnosanit Pregled 2016;73:895-903.

27. Brosky ME, Pesun IJ, Lowder PD, Delong R, Hodges JS. Laser digitization of casts to determine the effect of tray selection and formation technique on accuracy. J Prosthet Dent 2002; 87: 204-9.

28. Queiroz DA, Cunha LG, Duarte JLP, Neves ACC, Silva-Concilio LR. Influence of the casting material on the dimensional accuracy of dental dies. Braz Oral Res 2011;25:357-61.

29. Luthardt RG, Kühmstedt $P$, Walter MH. A new method for the computer-aided evaluation of three-dimensional changes in gypsum materials. Dent Mater 2003;19:19-24.

30. Kenyon BJ, Hagge MS, Leknius C, Daniels WC, Weed SC. Dimensional accuracy of 7 die materials. J Prosthodont 2005;14:25-31.

31. Pandey A, Mehtra A. Comparative study of dimensional stability and accuracy of various elastomeric materials. J Dent Med Sci 2014;13:40-5.

32. Ahmad M, Balakrishnan D, Narayan AI. A comparative evaluation of linear dimensional accuracy of the dies obtained using three conceptually different die systems in the fabrication of implant prosthesis: an in vitro study. Indian J Dent Res 2014;25:197-203.

33. Vigolo P, Millstein PL. Evaluation of master cast techniques for multiple abutment implant prostheses. Int J Oral Maxillofac Implants 1993; 8: 439-46.
34. Persson AS, Odén $A$, Andersson $M$, SandborghEnglund G. Digitization of simulated clinical dental impressions: virtual three-dimensional analysis of exactness. Dent Mater 2009;25:929-36.

35. de Avila ED, Barros LA, Del'Acqua MA, Castanharo SM, Molo F de A. Comparison of the accuracy for three dental impression techniques and index: an in vitro study. J Prosthet Res 2013;57:268-74.

36. Stober T, Johnson GH, Schmitter M. Accuracy of the newly formulated vinyl siloxanether elastomeric impression material. J Prosthet Dent 2010; 103: 228-39.

37. Ender A, Mehl A. Full-arch scans: conventional versus digital impressions-an in-vitro study. Int J Comput Dent 2011;14:11-21.

38. DeLong R, Heinzen M, Hodges JS, Ko CC, Douglas WH. Accuracy of a system for creating 3D computer models of dental arches. J Dent Res 2003; 82: 438-42.

39. Güth JF, Keul C, Stimmelmayr M, Beuer F, Edelhoff D. Accuracy of digital models obtained by direct and indirect data capturing. Clin Oral Invest 2013; 17: 1201-8.

40. Shembesh M, Ali A, Finkelman M, Weber HP, Zandparsa $R$. An in vitro comparison of the marginal adaptation accuracy of CAD/CAM restorations using different impression systems. J Prosthodont. 2017;26:581-6.

41. Vandeweghe $S$, Vervack $V$, Vanhove $C$, Dierens $M$, Jimbo R, De Bruyn H. Accuracy of optical dental digitizers: an in vitro study. Int J Periodontics Restor Dent 2015;35:115-21.

42. Martins LM, Lorenzoni FC, Melo AO, Silva LM, Oliveira JL, Oliveira PC, Bonfante G. Internal fit of two all-ceramic systems and metal-ceramic crowns. J Appl Oral Sci 2012;20:235-40.

\author{
Yazışma Adresi \\ Dr. Faruk EMİR \\ Sağlık Bilimleri Üniversitesi, \\ Gülhane Diş Hekimliği Fakültesi, \\ Protetik Diş Tedavisi AD-06010/ANKARA \\ Telefon: 03123046059 \\ E-mail: emirfaruk@gmail.com
}

